\title{
Políticas públicas para o livro e a leitura e sua influência na indústria editorial de Salvador
}

\author{
Othon Jambeiro* \\ Jussara Borges $^{* *}$ \\ Susane Barros ${ }^{* * *}$
}

Resumo O trabalho analisa as políticas nacionais e locais de promoção do livro e da leitura e seus reflexos na indústria editorial de Salvador. A metodologia envolveu entrevistas com atores da cadeia produtiva editorial, levantamento de dados junto às editoras e análise das políticas existentes. Entre outras conclusões sugere-se a criação e/ou desenvolvimento de bibliotecas públicas e escolares, a elas conferindo recursos financeiros para a aquisição de livros nas editoras locais.

Palavras-chave indústria editorial-Salvador; produção editorial-Salvador, livro, política do livro, economia política do livro

\begin{abstract}
This paper aims at identifying and analyzing Brazilian national and local policies on promoting literacy and the effects those policies have on the publishing industry situated in Salvador, Bahia. Methodology includes interviews with actors in that industry network of production and consumption; collection and analysis of data from publishing houses; analysis of public policies on book publishing and literacy. The conclusion shows the need for implementation of policies on supporting private initiatives and investments in that industry; and the creation and/or development of school and public libraries, providing the necessary funds to acquire books in local publishing houses.
\end{abstract}

Key-words publishing industry-Salvador, book production-Salvador, book, book policies, book political economy

\section{Introdução}

Apesar de ser colocada como prioridade na legislação e em programas sociais, a educação no Brasil precisa superar antigos obstáculos, que têm origem nos mesmos fatores econômicos, sociais e políticos que causam nossa profunda desigualdade social. A Constituição Federal tem como

\footnotetext{
${ }^{*} \mathrm{PhD}$ (University of Westminster, Londres) e Professor Titular do ICI/UFBA

** Mestre em Ciência da Informação (ICI/UFBA) e Professora Substituta do ICI/UFBA

*** Bibliotecária, aluna especial do Mestrado em Ciência da Informação do ICI/UFBA e bolsista de apoio técnico do CNPq no ICI/UFBA
} 
fundamentos a cidadania e a dignidade da pessoa humana, e coloca como objetivos fundamentais da União o desenvolvimento nacional, a erradicação da pobreza, a redução das desigualdades sociais e regionais e a promoção do bem de todos. Para que esses objetivos sejam efetivamente alcançados, sabe-se que antes de tudo é preciso oferecer educação de qualidade à população. A Educação se coloca, pois, como o maior desafio para que o Brasil consiga atingir os objetivos constitucionais. E o hábito da leitura permeia inteiramente esta questão.

Programas governamentais em curso propõem, por meio de diversas ações, elevar o índice de leitura da população brasileira de aproximadamente dois livros por ano para quatro, até 2007. Algumas das ações que vêm sendo desenvolvidas beneficiam diretamente os produtores do livro, já que se pretende apoiar a abertura de mil livrarias e financiar empresas do setor editorial.

O Programa Nacional do Livro e Leitura (PNLL) tem como meta zerar o número de municípios sem bibliotecas públicas. Pretende-se adquirir, para cada biblioteca implantada, 2.500 títulos, sendo 2.000 deles - caracterizados como acervo básico - selecionados por uma equipe técnica, dentro de um espectro de oferta aberto a todas as editoras. Os outros 500 serão adquiridos nos próprios Estados. Isto é importante porque o Brasil tem culturas regionais muito diferenciadas, que requerem diálogo e expressão própria para sobreviverem e se desenvolverem. Além disso, a aquisição de livros nos próprios Estados fortalece as editoras regionais e minora as desigualdades, já que hoje é forte a concentração de editoras no Centro-Sul do País.

Este trabalho busca identificar e analisar as políticas nacionais e locais de promoção do livro e de incentivo à leitura, fixadas pelos vários níveis de governo, e seus reflexos na indústria editorial de Salvador. A metodologia envolveu a realização de entrevistas com atores da cadeia produtiva editorial; levantamento de dados junto às editoras; análise das políticas relativas ao livro e à leitura; tratamento e análise dos dados. O quadro de referência conceitual e contextual, os procedimentos utilizados e os resultados alcançados são expostos a seguir.

\section{A educação na Sociedade da Informação}

A Sociedade da Informação, caracterizada por mudanças profundas em relação ao modelo industrial e estimulada por avanços tecnológicos, é uma realidade que ainda exclui a imensa maioria da população mundial, particularmente nos chamados países do terceiro mundo, como é o caso do Brasil. Esse aspecto é agravado especialmente pela falta de acesso à educação, já que este é um fator primordial para o funcionamento de uma sociedade que se baseia na informação.

Segundo dados do Instituto Nacional de Estudos e Pesquisas Educacionais Anísio Teixeira (INEP), existiam no Brasil, em 2004, mais de 16 milhões de analfabetos, sendo que a região Nordeste concentra quase $50 \%$ desse contingente. Considerando os analfabetos funcionais, caracterizados como pessoas com menos de quatro séries concluídas, são mais de 33 milhões de analfabetos. A esses indicadores pode-se relacionar o baixo desenvolvimento econômico dessas regiões e, consequientemente, as desigualdades regionais. A Bahia está entre os cinco Estados onde se situa metade dos analfabetos do País, na distribuição total de analfabetos absolutos. E apesar de ser, dentre eles, o que mais possui escolas, apresenta o menor percentual de bibliotecas escolares: 7,06\% (LIVRO..., 2005). 
Esses dados confirmam que, no Brasil, uma expressiva parcela da população não tem condições de desenvolver o hábito de leitura. Embora as escolas sejam espaços adequados para o contato do indivíduo com essa prática, o que se verifica é que elas não têm sido exploradas como tal.

Segundo Cropani (1998), baseado em estudos globais encomendados pela Unesco, os fatores críticos no estabelecimento do hábito de leitura de um povo ou mesmo de um indivíduo são: ter nascido numa família de leitores; ter passado a juventude num sistema escolar preocupado com o estabelecimento do hábito de leitura; o preço do livro; e o valor simbólico que a população lhe atribui.

Refletindo os problemas educacionais brasileiros, o resultado do Programa Internacional de Avaliação de Alunos (PISA), do ano de 2001, coloca o Brasil como um dos "lanterninhas" em interpretação de textos. O Pisa avalia se as escolas estão preparando os jovens para desafios futuros e identifica o nível de apreensão de conteúdos e habilidades para a efetiva participação na sociedade. O Programa é coordenado pela Organização para Cooperação e Desenvolvimento Econômico (OCDE) e no Brasil o INEP é o responsável por sua aplicação. Três áreas são avaliadas: leitura, matemática e ciência. Na prova de leitura, o Brasil ficou com a $37^{a}$ colocação, numa classificação de 41 países. A razão desse resultado negativo é atribuída, dentre outras causas, aos baixos investimentos em educação, já que foi comparado o gasto médio dos países, por aluno. Mas isso acaba sendo muito relativo porque depende, especialmente, do bom aproveitamento dos recursos e de sua real chegada às escolas, tendo em vista os recorrentes casos de corrupção envolvendo o desvio de verbas públicas da Educação.

Nesse contexto, Soares (2003) aponta para o letramento como algo importante e que se distingue da alfabetização, porque existe uma grande diferença entre aprender o código e saber utilizá-lo. A autora defende que os conceitos estão imbricados, de forma que entre eles não existe hierarquia ou cronologia. "Pode-se letrar antes de alfabetizar ou o contrário" (SOARES, 2003). Buzato (2003) acredita que o letramento alfabético é a base para o letramento digital e o define como "um conjunto de conhecimentos que permite às pessoas participarem nas práticas letradas, mediadas por computadores e outros dispositivos eletrônicos do mundo contemporâneo".

Com o surgimento de novos suportes de acesso à informação, o desafio duplica-se, pois que agora, além de alfabetizar, existe a importância de se colocar os indivíduos em contato com as tecnologias de informação e comunicação (TIC). Junto a isso, é perceptível a exigência cada vez maior do mercado de trabalho em busca de profissionais que dominem essas tecnologias.

A Sociedade da Informação traz em seu bojo a responsabilidade de criar valores que vão além da capacitação tecnológica. Antes de qualquer coisa é preciso estabelecer uma base de sustentação e atentar para o fato de que o indivíduo formado para esta sociedade deve ter visão crítica, consciência de sua identidade e ser capaz de exercer a cidadania, participando mais ativamente do processo político e cultural. Segundo Capurro (2002, p.12):

Enseñar a leer y escribir y conjuntamente también enseñar a pensar y a investigar significan hoy día, en una cultura digital, enseñar a utilizar los nuevos medios de información y comunicación, despertando el interés por el desarrollo de sí mismo, como individuo y como comunidad, en vistas a una cultura en la que se entrelacen el face to face y el interface. 
Para isso, faz-se necessário o estabelecimento de políticas que contemplem uma visão de sociedade em rede, pois a tendência é que os conteúdos migrem cada vez mais para o meio digital. A criação dos chamados "governos eletrônicos" (e-gov) tem como justificativa e objetivo essenciais a interação entre o poder público e a sociedade, por meio de tecnologias avançadas de informação e comunicações. Isto reforça a obrigação do Estado, em duas frentes: além de disponibilizar informações, ele tem de capacitar os indivíduos para acessá-las. Se essa barreira não for superada o fosso existente entre incluídos e excluídos se tornará ainda mais acentuado.

Outro aspecto que deve ser considerado é o acesso da população aos bens culturais, tradicionalmente posto em segundo plano, vez que a ação do Estado sempre esteve mais voltada para o apoio aos artistas. No Brasil, no início do século XIX, eles eram protegidos pela corte, ganhavam viagens pela Europa e seus projetos eram financiados pelo governo. Além disso, muitos conseguiam um emprego público. "Na literatura podiam-se premiar os poetas e romancistas da elite com sinecuras, como postos diplomáticos (Raul Pompéia), cargos na burocracia (Machado de Assis) e até na política (José de Alencar virou senador)”, como assinala Lindoso (2004, p. 25).

A produção intelectual não era analisada e valorizada pelo público e sim pelo círculo de intelectuais, a quem o governo oferecia benesses de toda natureza. As políticas culturais desenvolvidas no País resultaram, em grande medida, dessa relação, que, de alguma forma, perdura até os dias atuais. Programas como o FazCultura, por exemplo, terminam por beneficiar empresas e um certo círculo de intelectuais. Ou seja, o governo deixa de arrecadar impostos que poderia aplicar em projetos culturais e oferece incentivos fiscais para o financiamento de espetáculos e eventos que, em geral, pouco revertem em benefício do público.

\section{As políticas brasileiras para o livro}

Desde que a indústria editorial se implantou no Brasil, no início do século XIX, sempre houve políticas públicas voltadas para o livro. O que tem variado é o caráter dessas políticas, que transitam entre o controle, a repressão, a distribuição gratuita, o incentivo à leitura, o estímulo à produção, a apreensão e mesmo a pura e simples queima de livros. Além disso, elas têm se constituído em programas descontinuados. Não há comprometimento de um governo para outro na manutenção de programas criados por gestões anteriores. Praticamente tudo é descartado e feito novamente.

Nos anos recentes, particularmente a partir do final do século XX, diversas políticas novas surgiram, de caráter positivo, sendo as mais conhecidas as que são expressas na chamada Lei Rouanet (BRASIL, 1991), na Lei do Direito Autoral (BRASIL, 1998) e na pomposa Política Nacional do Livro (BRASIL, 2003). Além delas, em dezembro de 2004 o governo federal anunciou a edição de uma Medida Provisória - a MP do Livro - pela qual as editoras, distribuidoras, livrarias e importadoras de livros seriam desoneradas de uma carga fiscal que varia de 3,65\% a 9,25\%, na forma de contribuições para o PIS, COFINS e PASEP. A compensação pela desoneração fiscal da MP do Livro é uma contribuição dos beneficiados igual a $1 \%$ sobre as vendas, visando constituir o Fundo Pró-leitura. Este Fundo está sendo formado por representantes de entidades do livro Câmara Brasileira do Livro (CBL), Sindicato Nacional dos Editores de Livros (SNEL), Associação Brasileira de Editores de Livros (ABRELIVROS), Associação Nacional de Livrarias (ANL) e Associação Brasileira de Difusão do Livro (ABDL) - que irão administrar diretamente o fundo como uma das formas de financiar as políticas públicas para o livro e a leitura. Outras políticas têm sido expressas não em legislação, mas em programas governamentais, alguns de nomes nitidamente 
propagandísticos, como é o caso do Fome de Livro, outros com aparência de maior seriedade, como o Proler e o Vivaleitura, este delimitado no tempo, por ser o nome fantasia do Ano Ibero-Americano da Leitura, fixado em 2005.

A Lei Rouanet data de 1991 e não é específica para o livro. Ela abrange toda a área da Cultura, latu senso, e, além de instituir o Programa Nacional de Apoio à Cultura (PRONAC) e a Comissão Nacional de Incentivo à Cultura (CNIC), cria as condições para a captação e a canalização de recursos de empresas destinados a projetos culturais. Na verdade, ela cita o livro apenas uma vez e se mostra mais voltada para outros tipos de atividades culturais, embora, sob a rubrica de "obra", o livro esteja presente em várias de suas disposições.

Aclamada por uns e reprovada por outros, dividindo opiniões desde sua publicação, a Lei Rouanet (nome do seu formulador, o diplomata e filósofo Sergio Paulo Rouanet) propõe-se, entre outras ações, a: contribuir para o livre acesso às fontes de cultura; estimular a regionalização da produção cultural e artística; difundir manifestações culturais; proteger expressões culturais de grupos específicos da sociedade brasileira; preservar os bens materiais e imateriais do patrimônio nacional; estimular a produção e a difusão de bens culturais de valor universal; e priorizar o produto cultural brasileiro. Ela é tão criticada quanto a Lei Sarney, sua antecessora e primeira tentativa de fomento à cultura envolvendo empresas. Isto porque os livros, embora editados por meio dos incentivos fiscais, têm chegado aos consumidores com preços muito altos. Tanto que recentemente a Lei Rouanet passou por uma revisão jurídica, visando, entre outras coisas, garantir à população maior acesso aos bens culturais.

O Fundo Nacional da Cultura (novo nome do antigo Fundo de Promoção Cultural), subordinado ao Ministério da Cultura, foi designado como o depositário dos recursos a serem captados das empresas e outros meios previstos, entre os quais $1 \%$ da arrecadação dos fundos de investimentos regionais e 3\% das loterias federais. A Lei cria um novo Fundo, o de Investimento Cultural e Artístico (FICART), vinculado à Comissão de Valores Mobiliários, autarquia ligada ao Ministério da Fazenda. Os dois fundos passaram a ser as principais fontes de financiamento de projetos de natureza cultural no Brasil.

A Lei 9.610, de 19 de fevereiro de 1998, ou Lei do Direito Autoral, altera, atualiza e consolida a legislação sobre o assunto existente no País. Baseada em convenções internacionais assinadas pelo Brasil, juntamente com quase todos os países do mundo, ela regula o direito do autor sobre sua obra, definindo-a nas suas variadas formas de expressão (do livro ao software), estabelecendo as formas de controle e estipulando a duração de tempo em que este direito poderá ser exercido.

A Lei 10.753, de 30 de outubro de 2003, contudo, é mais complexa. Ela institui a Política Nacional do Livro e é, portanto, mais especificamente relacionada a este suporte material, virtual ou digital de informações. Trata-se de uma Lei que demanda regulamentação detalhada de suas disposições, o que ainda está por ser feito. As diretrizes nela fixadas abrangem, entre outras: o exercício do direito de acesso ao livro; o apoio à sua produção e difusão; o estímulo à produção de autores brasileiros; o incentivo ao hábito de leitura; o apoio à exportação; a ampliação do número de livrarias e bibliotecas no País; o acesso de deficientes visuais à leitura.

Descrentes dos avanços tecnológicos e das transformações previstas para o campo da informação e do conhecimento, os autores da Lei definem o livro como

o meio principal e insubstituível [grifo nosso] da difusão da cultura e transmissão do conhecimento, do fomento à pesquisa social e científica, da 
conservação do patrimônio nacional, da transformação e aperfeiçoamento social e da melhoria da qualidade de vida (BRASIL, 2003).

Trata-se, pois, de uma panacéia, isto é, um objeto que pode curar vários males. E mais, destaque-se: "principal e insubstituível”!

Além de conceitos, a Lei 10.753 trata também de aspectos técnicos e financeiros e de definições (o que são autor, editor, distribuidor etc.), obrigações dos governos federal, estadual e municipal (a quem cabe consignar, em seus orçamentos, recursos para manutenção das bibliotecas e aquisição de livros). O Fundo Nacional de Cultura, instituído como um dos mecanismos do Programa Nacional de Apoio à Cultura (PRONAC) estabelecido pela Lei Rouanet, é indicado como o destinatário dos recursos que sejam alocados pelo governo federal para "financiamento da modernização e expansão do sistema bibliotecário e de programas de incentivo à leitura".

A Lei do Livro é acusada de destinar-se quase que exclusivamente à proteção da indústria editorial e do comércio livreiro. Sua regulamentação tem sido discutida em vários encontros locais e nacionais, de onde têm saído muitas sugestões que reduzem aquela proteção e ampliam seu alcance social. Mas só o futuro dirá quem terá mais força na redação do decreto regulador.

Dessas políticas, consagradas em legislação, descendem os programas nacionais voltados para o setor. Três deles parecem ter obtido destaque: o Programa Fome de Livro, o Proler e o VivaLeitura. Todos estão devotados ao mesmo campo e se superpõem em várias das suas ações. O primeiro, por exemplo, se define como um "programa nacional de biblioteca pública e leitura". Chegou a constituir em 2005 uma comissão nacional para selecionar os livros a serem adquiridos para distribuição nas bibliotecas que estão sendo implementadas com o objetivo de zerar o número de municípios sem bibliotecas. As editoras poderiam ter inscrito livros de ficção, não-ficção e infantojuvenis, disponíveis em seus catálogos, e enviado um exemplar de cada título para a comissão, mas ao que parece o planejamento não foi adiante. O segundo "articula iniciativas de promoção de leitura". E o terceiro, usando uma linguagem muito ao gosto de propagandistas políticos, pretende ser um "marco para o início de um gigantesco esforço de todos para que o Brasil implemente uma Política Nacional do Livro, Leitura e Bibliotecas".

Esses programas, com exceção do Proler, existente há mais de 15 anos, não foram ainda avaliados. Não se sabe, portanto, que consequiências terão e se conseguirão alcançar os objetivos a que se propõem. Mas é fácil perceber que a desconcentração de esforços, energia e recursos financeiros e materiais muito provavelmente deverá levar a uma relação de custo-benefício muito alta.

\section{As políticas para o livro na Bahia}

$\mathrm{Na}$ Bahia, reconhecendo a necessidade de haver políticas e programas que garantam e estimulem a produção e circulação do livro no Estado, a Câmara Baiana do Livro, juntamente com a Fundação Pedro Calmon, elaborou e está submetendo à discussão um projeto de lei, com o subtítulo Política Estadual do Livro. Suas principais diretrizes são: democratizar o uso do livro; propiciar a criação de bibliotecas, livrarias e outros pontos de venda; incentivar o hábito de leitura; e fomentar a produção e a comercialização do livro baiano, incrementando sua qualidade e reduzindo seu preço. O projeto de lei prevê a elaboração anual de um Plano de Difusão do Livro, que contará com recursos do 
Tesouro Estadual. Ela prevê também "planos de formação, capacitação e aperfeiçoamento de recursos humanos alocados na cadeia produtiva do livro e da comunicação editorial".

Baseada na Lei do Livro federal, o projeto de lei repete algumas disposições daquela, mas inova em vários aspectos. O principal deles é um ostensivo privilégio do autor e da editora da Bahia. Outra inovação é a obrigatoriedade de todas as escolas manterem uma biblioteca para uso dos alunos e também da comunidade.

Por enquanto, o projeto sequer foi encaminhado à Assembléia Legislativa, a quem cabe examiná-lo e aprová-lo. Submetido ainda à discussão no âmbito da sociedade, ele terá de passar, igualmente, no crivo do ambiente interno do governo do Estado.

De concreto, quanto a políticas devidamente regulamentadas no âmbito do Estado da Bahia, existe em vigor o Decreto 9.232, de 22 de novembro de 2004, que regula o Programa Estadual de Incentivo à Cultura, criado pela Lei 7.015, de 09 de dezembro de 1996. Essa Lei dispõe sobre a concessão de incentivo fiscal para financiamento de projetos culturais e foi feita à luz da Lei Rouanet, de origem federal. De caráter geral para o campo da cultura, ela sequer menciona a palavra livro. Essa fonte de informação e conhecimento fica compreendida dentro da palavra "obra", e seus conteúdos entendidos como "literatura".

De qualquer forma, a Lei baiana tem dado suporte a diversos projetos culturais que contemplam a edição de livros, embora o maior volume de recursos do FazCultura (nome fantasia do Programa) se destine a outras áreas da cultura.

\section{Procedimentos}

Para melhor conhecer o perfil da atividade editorial em Salvador, realizou-se um levantamento sistemático de dados, com base na aplicação de questionários e entrevistas. Os procedimentos incluíram: um mapeamento inicial das editoras, a partir de pesquisa junto à Câmara Baiana do Livro (CBal); em seguida, uma primeira abordagem aos responsáveis pelas editoras, por telefone, com o objetivo de apresentar o trabalho a ser realizado e marcar horários para a aplicação dos questionários.

Delimitado assim o universo a ser pesquisado, foram feitas entrevistas, visando a um aprofundamento na compreensão da atividade editorial e, ao final, foi aplicado um questionário destinado ao levantamento de dados.

O questionário incluiu, dentre outras, questões referentes às tecnologias utilizadas no processo editorial, número de títulos publicados em catálogo, média anual de publicações, média das tiragens e linha editorial. As entrevistas foram direcionadas para coletar informações sobre a opinião dos gestores das editoras em relação às políticas e ações que vêm sendo promovidas e divulgadas pelos governos. Foi perguntado, dentre outras coisas, se eles têm acompanhado as ações do governo para o livro e a leitura; quais suas expectativas em relação a esta mobilização; o impacto para o mercado editorial que a desoneração fiscal causará; a contribuição deles para a constituição do Fundo PróLeitura; se investem em livros patrocinados através das leis de incentivo à cultura; e se inscreveram títulos para o Programa Fome de Livro. O tratamento dos dados foi feito com o auxílio do programa Excel. 


\section{Análise de dados}

Foram levantadas 10 editoras privadas: P555 Designers Gráficos e Edições, Editora Helvécia, Ágalma Psicanálise Editora, Editora Casa de Palavras, Editora Calandra, Casa da Qualidade Editora, Contexto e Arte Editorial, Editora Corrupio, Maianga Produções Culturais, Editora Leal. Além disso, existem três órgãos públicos que exercem atividade editorial: Secretaria de Cultura e Turismo do Estado da Bahia / Fundação Cultural do Estado da Bahia, Superintendência de Estudos Econômicos e Sociais da Bahia, Assembléia Legislativa do Estado da Bahia. O conjunto é fechado com cinco editoras universitárias: Edufba, Eduneb, HR Editora, Editora da FTC, Editora da FIB.

A análise de dados do primeiro questionário baseou-se numa coleta inicial, feita com o objetivo de caracterizar e traçar um perfil do setor na Cidade. Para efeito de sua aplicação foram desconsiderados os órgãos públicos, observando os seguintes critérios: não terem a produção editorial como missão principal, não produzirem com regularidade, não serem representativos em termos comerciais e não possuírem estrutura adequada para o desenvolvimento da atividade.

Os resultados indicam que 46,66\% das editoras têm até cinco anos de fundação. Apenas 26,66\% têm entre 15 e 35 anos. Isto sugere que, das editoras existentes entre as décadas de 50 e 80, poucas resistiram aos embates do mercado, terminando por sucumbir. O fenômeno é também um indicador de que o mercado tem poucas editoras consolidadas e, portanto, capazes de atuar no nível nacional.

Mais de $60 \%$ das editoras que responderam ao questionário pretendem atingir o público em geral, mas por apresentarem linhas editoriais muito definidas acabam atingindo um público restrito, apesar de nem sempre haver intenção de atendimento a demandas específicas. É o caso das editoras universitárias, que embora publiquem livros tratando de assuntos variados, utilizam uma linguagem pouco atraente para o público em geral. Da mesma forma, a editora de livros religiosos (espíritas), embora afirme publicar para o público em geral, tem publicações que interessam mais especificamente aos seus fiéis.

Mais de $26 \%$ das editoras publicam apenas autores baianos, apesar de não terem formulado políticas expressas quanto a isso. Uma delas, contudo, apresenta linha editorial específica para publicação de originais oriundos do Estado.

Um total de $60 \%$ das editoras trabalha numa modalidade que inclui a participação financeira do autor, alegando que são empresas e precisam ter lucratividade. Além disso, argumentam que esta forma de atuar abre espaço para pessoas que sempre quiseram publicar um livro, mas nunca conseguiram ter seus originais aceitos. Mesmo entre faculdades e universidades encontra-se esta modalidade de publicação, às vezes subsidiada com recursos de órgãos financiadores e de fomento à pesquisa. Apenas uma editora tem conselho editorial. Conseqüentemente, os textos que a maioria delas publica não passam pelo crivo de especialistas, ficando portanto ameaçada a qualidade dos produtos.

A co-edição, entendida como a edição de uma publicação que é realizada por meio de convênio entre dois ou mais editores, é utilizada por $66,66 \%$ das editoras. Normalmente envolve a divisão do processo de edição e dos custos, sendo a tiragem dividida e o preço de capa combinado, para não haver concorrência entre as duas, no momento da comercialização. 
Apenas 6,66\% possuem parque gráfico, o que cria uma demanda por gráficas especializadas em impressões de livros. Muitas das gráficas existentes em Salvador são vistas pelos editores como concorrentes despreparadas das gráficas de outros Estados, como São Paulo e Rio de Janeiro, já que possuem preços mais altos e oferecem uma qualidade de impressão inferior. Por isso preferem mandar fazer as impressões em outro Estado, onde a qualidade é melhor e os preços menores, a ponto de ser economicamente viável, mesmo incluindo o pagamento do transporte dos materiais. Isto ocorre não por falta de investimentos em tecnologias avançadas, mas sim por ausência de mãode-obra qualificada.

Segundo dados fornecidos pelas editoras, $40 \%$ publicaram, ao longo de sua existência, até 10 títulos. Mais de 46,66\% possuem uma média anual de até 5 publicações (Gráfico 1). Considerando que hoje o sistema de impressão sob demanda é muito utilizado, $40 \%$ trabalham com uma tiragem entre 500 e 1.000 exemplares (Gráfico 2).
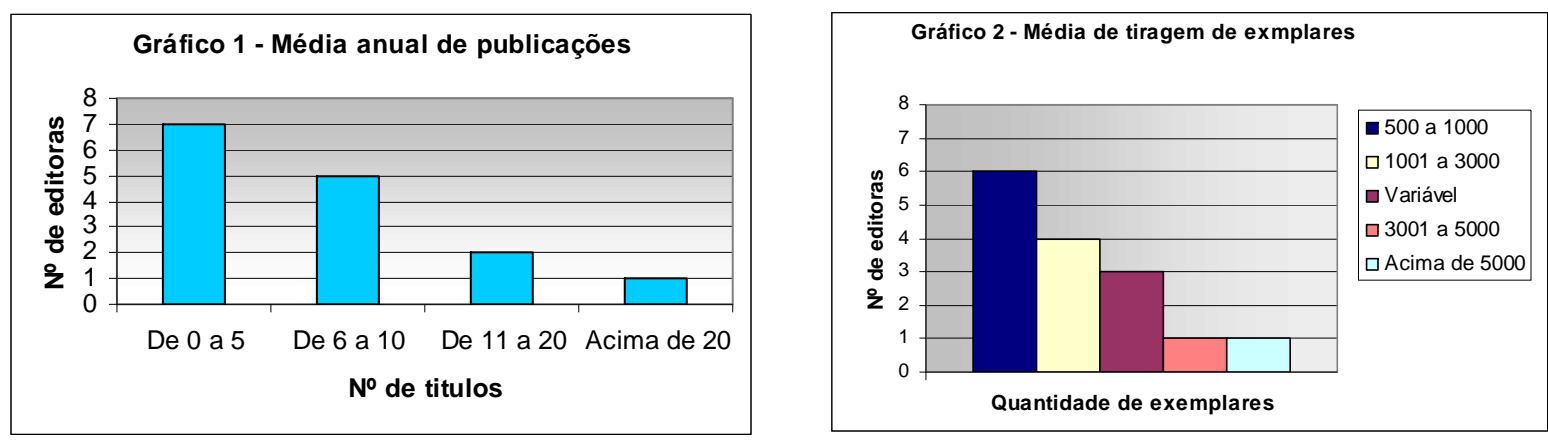

Para dar continuidade à pesquisa foi estabelecido como critério entrevistar apenas as editoras associadas à Câmara Baiana do Livro, isto é, aquelas com reconhecimento de atividade regular e continuada, por parte do mercado. Isto reduziu a população a 8 editoras (7 privadas e uma universitária).

Quando questionadas quanto ao acompanhamento das ações que vêm sendo desenvolvidas pelo governo federal, todas as editoras declararam estar a par delas, participando, inclusive, de debates promovidos pela CBal, em Salvador. Dois entrevistados revelaram-se, contudo, descrentes delas, pois acreditam que a região acaba sendo pouco beneficiada.

Os entrevistados acreditam que as conseqüências da desoneração fiscal serão, em primeiro lugar, a retomada de investimentos por parte de editoras e livrarias; em segundo, a redução dos preços dos livros; e, por último, prevêm que a desoneração só terá efeito se outras ações forem realizadas.

Em relação à constituição do Fundo Pró-Leitura, apenas dois entrevistados se disseram comprometidos com a iniciativa, enquanto seis desconhecem a ação empreendida ou julgam pouco provável que seja tratada com seriedade. Um deles afirmou que sua editora,

[...] a exemplo da maior parte das pequenas editoras, não obteve nenhum benefício com a chamada desoneração fiscal, pois o Simples substitui a 
contribuição que foi desonerada. Assim, o pagamento de $1 \%$ é algo a mais e não troca por um imposto abatido.

$\mathrm{Na}$ verdade, embora tenha sido deliberado pelas entidades nacionais vinculadas ao livro, em março de 2005, que o mercado editorial estaria iniciando imediatamente a contribuição voluntária de $1 \%$ sobre as vendas, até a data de aplicação dos questionários, nenhuma discussão sobre o assunto havia sido realizada em Salvador.

Outro ponto colocado nas entrevistas foi o investimento em livros patrocinados através das leis de incentivos à cultura. Apenas um entrevistado disse que utiliza a Lei Rouanet e três o Fazcultura. Os outros quatro apontam a burocracia como fator desestimulante ou acreditam não possuir títulos que possam despertar o interesse de patrocinadores, pelo caráter de suas linhas editoriais.

As respostas à pergunta sobre a inscrição de títulos no Programa Fome de Livro revelou que somente duas editoras participaram, apesar de não terem sido contempladas. Seis afirmaram não ter participado da seleção: cinco por não terem sequer tomado conhecimento da abertura das inscrições; e uma porque acredita que o programa apresenta um caráter de formação de leitores e, por suas linhas editoriais não se encaixarem nesse perfil, optou por não inscrever nenhum título.

\section{Considerações finais}

O conjunto dos resultados permite ver um perfil bastante jovem para as editoras soteropolitanas. Isto pode ser decorrência da dificuldade de competição, tanto em função das novas mídias - que emergiram no mesmo momento histórico de encerramento das atividades de muitas editoras - como de outras empresas do mesmo segmento, que constituíram conglomerados mais fortes economicamente em São Paulo e Rio de Janeiro e que atuam no mercado nacional.

A pouca maturidade do mercado editorial soteropolitano reflete-se também na sua baixa profissionalização, o que pode ser percebido, ainda que parcialmente, pelo desconhecimento ou pouca preocupação com a delimitação de seu público-alvo. Da mesma forma, a quase inexistência de conselhos editoriais nas editoras é outro elemento que denuncia essa baixa profissionalização, já que as editoras comumente passam a ser reconhecidas e aceitas no mercado, a partir da qualidade de seus produtos.

Em geral, são editoras pequenas, o que pode ser observado por sua baixa média de publicações anuais, quando comparadas com editoras do centro do País. Isso as leva a buscar cooperação com outras editoras e a restringir seus autores aos baianos, o que, por outro lado, pode ser apontado como um ponto positivo, na medida em que garantem espaço para a divulgação da produção científico-cultural local.

Pôde-se perceber em vários momentos, com alguns dos entrevistados, uma postura que reflete a baixa estima do setor em Salvador. Talvez este fator contribua para o lento desenvolvimento do mercado.

Igualmente notória foi a postura que alguns entrevistados manifestam diante dos esforços do governo: não possuem uma atitude proativa, no sentido de cobrar e acompanhar de perto estas ações 
que afetam e condicionam seu desenvolvimento. Decorrente ou não desta postura, o certo é que ainda não é possível perceber mudanças significativas na indústria editorial de Salvador, por força das ações que vêm sendo implementadas pelos governos.

O estudo conclui pela necessidade de implementação de políticas que estimulem iniciativas e investimentos na indústria editorial. Acredita-se que os investimentos devem ser feitos, sobretudo, para melhor qualificar os profissionais da área e estruturar a indústria local, de forma que possa ter alguma possibilidade de competição com empresas editoriais nacionais e internacionais que abastecem o mercado local. Além disso, a criação e/ou desenvolvimento de bibliotecas públicas e escolares, a elas conferindo recursos financeiros para a aquisição de livros nas editoras locais, é uma medida que pode dinamizar a economia e a cultura locais e fomentar o crescimento da indústria editorial em Salvador.

\section{Referências}

BAHIA. Constituição. Constituição do Estado da Bahia. Salvador: Assembléia Legislativa do Estado da Bahia, 1989. Disponível em: <http://www.bahia.ba.gov.br/assemb/infserv/legislacao/constituicao.pdf>. Acesso em: 10 fev. 2005.

BAHIA. Lei $\mathrm{n}^{\circ}$ 7.015, de 09 de dezembro de 1996. Dispõe sobre a concessão de incentivo fiscal para financiamento de projetos culturais. Salvador, BA, 9 dez. 1996. Disponível em: http://www.fazcultura.ba.gov.br/. Acesso em: 30 mar. 2005.

BAHIA. Decreto-lei $\mathrm{n}^{\circ}$ 9.232, de 11 novembro de 2004. Aprova o regulamento de programa Estadual de Incentivo à Cultura - FAZCULTURA e dá outras providências. Salvador, 12 nov. 2004. Disponível em: <http://www.fazcultura.ba.gov.br/>. Acesso em: 17 mar. 2005.

BRASIL. Constituição da República Federativa do Brasil. Brasília: Senado Federal, 1988. Disponível em:<https://www.planalto.gov.br/ccivil_03/Constituicao/Constitui\%C3\%A7ao.htm>. Acesso em: 10 fev. 2005.

BRASIL. Lei $\mathrm{n}^{\circ}$ 10.753, de 30 de outubro de 2003. Institui a política nacional do livro. Brasília, DF, 31 out. 2003. Disponível em: <https://www.planalto.gov.br/ccivil_03/LEIS/2003/L10.753.htm> Acesso em: 25 abr. 2004.

BRASIL. Lei $n^{\circ}$ 9.610, de 19 de fevereiro de 1998. Altera, atualiza e consolida a legislação sobre direitos autorais. Brasília, DF, 19 fev. 1998. Disponível em: <http://www.mct.gov.br/legis/leis/9610_98.htm>. Acesso em: 24 abr. 2004.

BRASIL. Lei $\mathrm{n}^{\circ}$ 8.313, de 23 de dezembro de 1991. Restabelece princípios da Lei $\mathrm{n}^{\circ} 7.505$, de 2 de julho de 1986, institui o Programa Nacional de Apoio à Cultura - PRONAC. Brasília, DF, 23 dez. 1991. Disponível em: http://www.minc.gov.br/legisl/docs/L-008313.htm. Acesso em: 17 mar. 2005.

BUZATO, Marcelo. Letramento digital abre portas para o conhecimento. Icoletiva, São Paulo, mar. 2003. Disponível em: <http://www.icoletiva.com.br/icoletiva/secao.asp?tipo=entrevistas\&id=15>. Acesso em: 14 mar. 2004. 
CAPURRO, Rafael. Perspectivas de una cultura digital en Latinoamerica. DataGramaZero, Rio de Janeiro, v.3, n. 2, abr. 2002. Disponível em: <http://www.dgzero.org/abr02/Art_01.htm>. Acesso em: 29 abr. 2005.

CROPANI, Otaviano De Fiore di. Livro, biblioteca e leitura no Brasil. Brasília: [s. n.], 1998. Disponível em:< http://www.minc.gov.br/textos/old_back/tm02.htm > Acesso em: 17 ago. 2004.

LINDOSO, Felipe. O Brasil pode ser um país de leitores? São Paulo: Summus, 2004.

LIVRO pra que te quero. A Tarde, Salvador, 6 mar. 2005. Local, p.3.

MINISTÉRIO DA EDUCAÇÃO. Instituto Nacional de Estudos e Pesquisas Educacionais Anísio Teixeira. Mapa do analfabetismo no Brasil. Brasília, DF. Disponível em: <http://www.inep.gov.br/estatisticas/analfabetismo/>. Acesso em: 13 abr. 2005.

SALVADOR. Lei 6586, de 3 de agosto de 2004. Dispõe sobre o Plano Diretor de Desenvolvimento Urbano do Município do Salvador, Salvador, BA, 3 ago. 2004. Disponível em: <http://www.seplam.pms.ba.gov.br/pddua/lei658604.asp >. Acesso em: 10 fev. 2005.

SOARES, Magda Becker. O que é letramento. Diário do Grande ABC, Santo André, ago. 2003. Seção Diário na Escola. Disponível em: http://www.diarionaescola.com.br/29se08.pdf>. Acesso em: 5 mar. 2004. 